\title{
Immediate alveolar buccal bone plate reconstruction. A simplified technique with 28 consecutive cases and 2- to 4-year follow-up. Case reports with hard tissue and aesthetic evaluation
}

\author{
Marzio Todisco \\ Private practice, Desenzano del Garda -Italy
}

\begin{abstract}
Purpose: The objectives of this study were to present a novel surgical technique for buccal bone plate regeneration and to evaluate the dimensions of the buccal bone and aesthetic parameters over a 2- to 4-year follow-up period.

Materials and methods: Twenty-eight patients participated in this prospective clinical study. After tooth/implant extraction, labial bone defects were grafted with xenogenic bone substitute and covered with a collagen membrane. An implant was placed eight months after the reconstruction surgery and loaded three months later. An evaluation of the hard and soft tissues was performed after a mean of 3 years of follow-up. Cone-beam computed tomography was performed to examine the stability over time and measure the thickness of the reconstructed buccal bone plate. The Pink Aesthetic Score was used to evaluate the aesthetic outcome of the peri-implant soft tissues. Patient satisfaction with aesthetics was also evaluated with a questionnaire 15 months after loading the implant.
\end{abstract}

Results and conclusions: All patients attended the follow-up examination. At the follow-up examination, the mean of the reconstructed facial bone thickness was greater than $2 \mathrm{~mm}$.

Based on the examinations using the Pink Aesthetic Score, $10.7 \%$ of the cases had a good outcome $(>9$ and $<12)$, and twenty-five out of $28(89.3 \%)$ had a perfect result $(>12)$.

Eleven patients out of 28 indicated good satisfaction, and 17 indicated excellent satisfaction fifteen months after the implant loading.

\section{Introduction}

The technique of placing titanium oral implants in healed edentulous sites and subsequently restoring the implant with prosthesis has been recognized to be a highly effective treatment for fully and partially edentulous patients.

In general, the 5 -year survival rate of implants is approximately $95 \%$, and the 10 -year survival rate is greater than $89 \%$ [1]. Nevertheless, over the years, researchers have tried to minimize the treatment time required, and therefore, the timing of the implant placement has recently gained considerable attention. One of the strategies proposed has been to place the implant immediately after tooth extraction. Successful management of the extraction socket can be challenging in the aesthetic zone, particularly if the buccal plate is compromised.

As such, immediate single implant treatment may be a risky procedure in terms of soft tissue stability, especially when patients are improperly selected and when surgery is performed by inexperienced clinicians [2].

Planning a surgical procedure in the case of implant placement at the post-extraction site must fulfil several pre-set clinical conditions, which include the best bone availability (horizontal, vertical, and contoured). The complete loss of the buccal bone plate could be one of the contraindications for placing the implant immediately after tooth extraction. In the event that an osseous defect presents on the facial bony plate, a delayed approach with hard or soft tissue grafting is usually recommended [3].

A high risk for advanced midfacial recession has been described following immediate implant treatment and simultaneous guided bone regeneration (GBR) of facial osseous defects [4].

Various clinical studies have demonstrated that $20 \%$ to $30 \%$ of immediate implants yield mucosal recessions of $>1 \mathrm{~mm}[5,6]$.

Nevertheless, attempts have been made to incorporate grafting to repair osseous defects simultaneously with immediate tooth replacement. Despite favourable initial outcomes, the long-term results of such procedures have been lacking.

Two recent studies using cone-beam computed tomography (CBCT) with immediately placed implants and simultaneous GBR

*Correspondence to: Marzio Todisco, via Agello 68/c Desenzano del Garda 25015 Italy, Tel: 39-030-990-1158, E-mail: marzio@marziotodisco.com

Key words: bone augmentation, aesthetic, implant, membrane, recession

Received: November 25, 2018; Accepted: December 10, 2018; Published: December 14, 2018 
Todisco M (2018) Immediate alveolar buccal bone plate reconstruction. A simplified technique with 28 consecutive cases and 2- to 4-year follow-up. Case reports with hard tissue and aesthetic evaluation

demonstrated a high percentage of implant sites without facial bone $[7,8]$.

Furthermore, the aesthetic aspects of reconstructive therapy have only been sporadically reported, even though these aspects are increasingly becoming the key to success in daily practice.

The aim of this prospective study was to present a novel surgical approach for the reconstruction of the buccal bone plate with delayed implant placement in cases of the complete loss of facial bone after tooth/implant extraction. The research hypothesis was that this treatment concept, with a staged approach, would demonstrate very stable outcomes at both the hard and soft tissue levels as well as good aesthetic results.

The patients were assessed clinically and radiographically after implant placement with a mean follow-up of 3 years. Aesthetic aspects and patient aesthetic satisfaction were also evaluated.

\section{Materials and methods}

This study included 28 healthy patients (age 21-67 years; mean 48.8) who were treated in a private practice by one experienced implant surgeon between March 2012 and February 2014. All the patients had an impending loss of a single tooth (incisor, canine or first premolar) or an implant. The exclusion-criteria were:

- Heavy smokers (more than 10 cigarettes a day)

- Patients under the age of 18 years

- Patients with a full-mouth plaque score $\geq 25 \%$
- Patients with non-treated periodontal diseases

The mode of tooth failure included the following:

1. trauma with root fracture, 3 cases;

2. root resorption, 2 cases;

3. root fracture, 11 cases; and

4. endodontic failure, 8 cases.

(Table 1 lists the causes for tooth extraction.)

Four patients required implant removal.

To be eligible, the failing implant had to have:

1. soft tissue recession at the facial site $>2 \mathrm{~mm}$;

2. buccal bone plate resorption for a minimum of half of the total length of the implant (measured by mean of periodontal probe);

3. severe exposure of the thread and incorrect placement and angulation in a buccal position;

4. an unfavourable aesthetic appearance while smiling with the exposure of the implant surface;

5. disharmony in the scalloping of the marginal soft tissues; and

6. natural adjacent teeth surrounding the implant without interproximal attachment loss;

(Table 1 lists the cases of implant extraction).

Table 1. Data regarding the patients, defect sites, biotype and soft tissue recession

\begin{tabular}{|c|c|c|c|c|c|c|}
\hline Patient & Gender & Age & Tooth & Reason for extraction & Biotype & $\begin{array}{l}\text { Soft tissue recession } \\
\qquad(2 \mathrm{~mm})\end{array}$ \\
\hline 1 & $\mathrm{~F}$ & 37 & 14 & root fracture & tk & $<$ \\
\hline 2 & $\mathrm{~F}$ & 54 & 23 & root fracture & tk & $<$ \\
\hline 3 & M & 30 & 22 & root resorption & tk & $<$ \\
\hline 4 & M & 63 & 23 & endodontic failure & tk & $<$ \\
\hline 5 & M & 40 & 12 & root fracture & tn & $=$ \\
\hline 6 & $\mathrm{~F}$ & 51 & 22 & trauma with root fracture & tk & $<$ \\
\hline 7 & M & 64 & 11 & endodontic failure & tk & $<$ \\
\hline 8 & M & 49 & 13 & root fracture & tk & $=$ \\
\hline 9 & M & 56 & 34 & root fracture & tk & $=$ \\
\hline 10 & $\mathrm{~F}$ & 55 & 34 & endodontic failure & tk & $<$ \\
\hline 11 & $\mathrm{~F}$ & 57 & 12 & endodontic failure & tn & $=$ \\
\hline 12 & $\mathrm{~F}$ & 48 & $12 \mathrm{i}$ & absence buccal bone & tk & $>$ \\
\hline 13 & $\mathrm{~F}$ & 60 & 21 & root fracture & tk & $<$ \\
\hline 14 & $\mathrm{~F}$ & 44 & $21 \mathrm{i}$ & absence buccal bone & tk & $>$ \\
\hline 15 & M & 52 & 34 & root fracture & tk & $=$ \\
\hline 16 & M & 38 & 11 & trauma with root fracture & tk & $<$ \\
\hline 17 & $\mathrm{~F}$ & 57 & 11 & root resorption & tn & $=$ \\
\hline 18 & $\mathrm{M}$ & 50 & $22 \mathrm{i}$ & absence buccal bone & tk & $>$ \\
\hline 19 & M & 50 & 23 & root fracture & tk & $<$ \\
\hline 20 & M & 46 & 13 & endodontic failure & tk & $<$ \\
\hline 21 & M & 25 & 14 & trauma with root fracture & tk & $<$ \\
\hline 22 & $\mathrm{~F}$ & 28 & $11 \mathrm{i}$ & absence buccal bone & tk & $>$ \\
\hline 23 & $\mathrm{~F}$ & 63 & 21 & endodontic failure & tk & $=$ \\
\hline 24 & $\mathrm{M}$ & 51 & 11 & root fracture & tk & $<$ \\
\hline 25 & $\mathrm{~F}$ & 67 & 22 & root fracture & tk & $=$ \\
\hline 26 & $\mathrm{~F}$ & 54 & 14 & endodontic failure & tn & $=$ \\
\hline 27 & $\mathrm{~F}$ & 21 & 12 & endodontic failure & tn & $=$ \\
\hline 28 & M & 58 & 24 & root fracture & tk & $<$ \\
\hline
\end{tabular}

$\mathrm{i}=$ implant; $\mathrm{tk}=$ thick; $\mathrm{tn}=$ thin 
Todisco M (2018) Immediate alveolar buccal bone plate reconstruction. A simplified technique with 28 consecutive cases and 2- to 4-year follow-up. Case reports with hard tissue and aesthetic evaluation

To be eligible, the failing tooth had to have:

1. a total osseous defect on the facial bony plate;

2. buccal periodontal probing $>6 \mathrm{~mm}$;

3. the absence of extensive gingival recession $(<2 \mathrm{~mm})$;

4. natural adjacent teeth surrounding the tooth without interproximal attachment loss; and

5. well-maintained bone/gingival architecture.

The surgical reconstruction technique was planned with a twostage approach: bone regeneration followed by implant therapy 8 months later.

Implant therapy, after bone reconstruction, had been determined to be the treatment of choice after clinical and radiographic evaluations, and all the patients consented to the treatment.

All the patients participated in maintenance care program with annual follow-up examinations and professional dental hygiene treatments once every 6 months.

The study was conducted in accordance with the fifth revised Helsinki Declaration.

All procedures and materials in the present study were approved by the local ethical committee.

\section{Site assessment}

The following soft tissue conditions were evaluated.

Soft tissue quality
- The soft tissue contour was characterized as adequate or compromised depending on the recession.

Soft tissue quantity

- The keratinized gingival width on the buccal side within the treatment area was determined using a millimeter standard periodontal probe (Hu-Friedy UNC, Chicago, IL, USA).

\section{Biotype}

- The gingival tissue biotype was characterized as thick $(>1 \mathrm{~mm})$ or thin $(<1 \mathrm{~mm})$ gingival tissue.

(Table 2 lists the quality and quantity of the soft tissue conditions listed above)

\section{Surgical protocol}

One hour before surgery, the patients were given $2 \mathrm{~g}$ of amoxicillin (Velamox 1 gr; Mediolanum Farmaceutici S.P.A., Milano, Italy), and $1 \mathrm{~g}$ was given 8 hours post-operatively. One tablet of an anti-inflammatory drug (ibuprophene $600 \mathrm{mg}$, Brufen; Abbott S.r.l. Campoverde, Latina Italy) was given to the patients 30 minutes prior to surgery, and 1 tablet was given 6 hours after the intervention. Oral disinfection was performed using a $0.2 \%$ chlorhexidine digluconate mouthwash (Dentosan clorexidina 0.20; Recordati S.P.A., Milano, Italy).

After local anesthesia, failing teeth/implants were gently extracted without flap reflection.

The vertical defect of the buccal bone (Table 2 lists the bone defects) was measured after tooth/implant extraction with a millimetre standard periodontal probe from the cemento-enamel junction (CEJ)

Table 2. Soft tissue quality, quantity, and buccal bone defect

\begin{tabular}{|c|c|c|c|c|}
\hline Patient & Quality & Quantity mm & Buccal bone defect M-D mm & Buccal bone defect C-A mm \\
\hline 1 & adequate & 3 & 7 & 10 \\
\hline 2 & adequate & 4 & 6 & 9 \\
\hline 3 & adequate & 3 & 6 & 9 \\
\hline 4 & adequate & 4 & 7 & 12 \\
\hline 5 & adequate & 1 & 4 & 10 \\
\hline 6 & adequate & 4 & 5 & 8 \\
\hline 7 & adequate & 3 & 5 & 13 \\
\hline 8 & adequate & 3 & 6 & 11 \\
\hline 9 & adequate & 3 & 5 & 9 \\
\hline 10 & adequate & 3 & 4 & 13 \\
\hline 11 & adequate & 2 & 6 & 10 \\
\hline 12 & compromised & 3 & 6 & 12 \\
\hline 13 & adequate & 3 & 5 & 15 \\
\hline 14 & compromised & 3 & 5 & 9 \\
\hline 15 & adequate & 2 & 7 & 14 \\
\hline 16 & adequate & 3 & 5 & 10 \\
\hline 17 & adequate & 1 & 4 & 8 \\
\hline 18 & compromised & 3 & 5 & 8 \\
\hline 19 & adequate & 4 & 5 & 12 \\
\hline 20 & adequate & 3 & 8 & 10 \\
\hline 21 & adequate & 3 & 5 & 10 \\
\hline 22 & compromised & 4 & 7 & 11 \\
\hline 23 & adequate & 2 & 6 & 9 \\
\hline 24 & adequate & 3 & 6 & 13 \\
\hline 25 & adequate & 2 & 7 & 12 \\
\hline 26 & adequate & 1 & 8 & 15 \\
\hline 27 & adequate & 1 & 8 & 11 \\
\hline 28 & adequate & 3 & 7 & 10 \\
\hline
\end{tabular}

$\mathrm{M}-\mathrm{D}=$ mesio-distal C-A = corono-apical 
Todisco M (2018) Immediate alveolar buccal bone plate reconstruction. A simplified technique with 28 consecutive cases and 2- to 4-year follow-up. Case reports with hard tissue and aesthetic evaluation

line of the adjacent teeth to the most apical point of the residual buccal bone.

The mesio-distal defect of the buccal bone was measured within the most coronal $3 \mathrm{~mm}$.

Full-thickness soft tissues of the adjacent teeth (mesially and distally to the extraction socket) were gently elevated (envelope flap) without any reflection nor released incision. The envelope flap was extended in the apical zone; thus, it was possible to have at least $3 \mathrm{~mm}$ of healthy socket bone all around the defect of the buccal bone plate.

A resorbable cross-linked collagen membrane (Cytoplast RTM Collagen; Osteogenics Biomedical, Inc., Lubbock, Texas, USA) was positioned in the envelope created during the soft tissue preparation to replace the buccal bone plate with the rigid membrane edge leaning against the bone all around the buccal defect. The membrane was never exposed on the top of the socket. The "new socket" was filled with particulate heterologous bone (Equimatrix, Equine xenograft; Osteogenics Biomedical, Inc., Lubbock, Texas, USA). A single crossed suture finally stabilized the graft. No sutures were required on the buccal aspect since the membrane was kept in place by the pressure of the graft against the buccal side, simultaneously preventing the collapse of the membrane.

Chlorhexidine $0.2 \%$ oral rinses were prescribed three times daily for 2 weeks. Then, patients were instructed to use an extra-soft toothbrush and rinse with chlorhexidine twice a day for one month.

The sutures were removed after 8 days. The patient was recalled for prophylaxis every 2 weeks after suture removal for the first 2 months.

Of the twenty-eight cases, 20 received a provisional crown splinted to the adjacent teeth immediately post-surgery.

After 8 months, CBCT (the first CBCT scan) was performed to evaluate the bone reconstruction procedure in three dimensions, and re-entry surgery for the implant placement was performed.

In all cases, the implant (NobelActive; Nobelbiocare, Kloten, Switzerland; Megagen Anyridge Megagen Implant, Gangnam-gu, Seoul, Korea) was positioned with a flap surgery to clinically assess the outcome of the buccal bone reconstruction by penetrating the regenerated tissue with a periodontal probe. Primary implant stability was measured over $35 \mathrm{~N} / \mathrm{cm}$, and the ideal three-dimensional positioning of the implant was obtained as described by Buser et al. [9]

Implant placement was performed using a submerged installation procedure. Osteotomy preparations were performed according to the standards described in the manual for surgical procedures of the implant system.

Three months after positioning, all the implants were loaded with a provisional cemented crown for a six-month period of "tissue conditioning" to obtain an optimal gingival contour and good relationship between the soft tissue and crown. Finally, a feldspathic porcelain crown (lithium-disilicate glass-ceramic restoration) was prepared and cemented over the abutment. All the abutments were titanium or zirconia abutments (see clinical case, Figures 1-12). All the single crowns were fabricated by the same dental technician (see protocol time table, Figure 13).

Evaluations of the soft and hard tissues were performed by two clinicians (M.S. and G.G.) who had not been involved in any of the treatments.

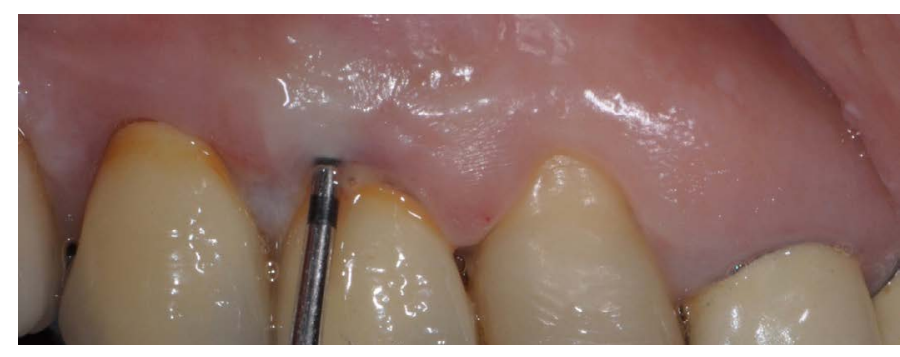

Figure 1

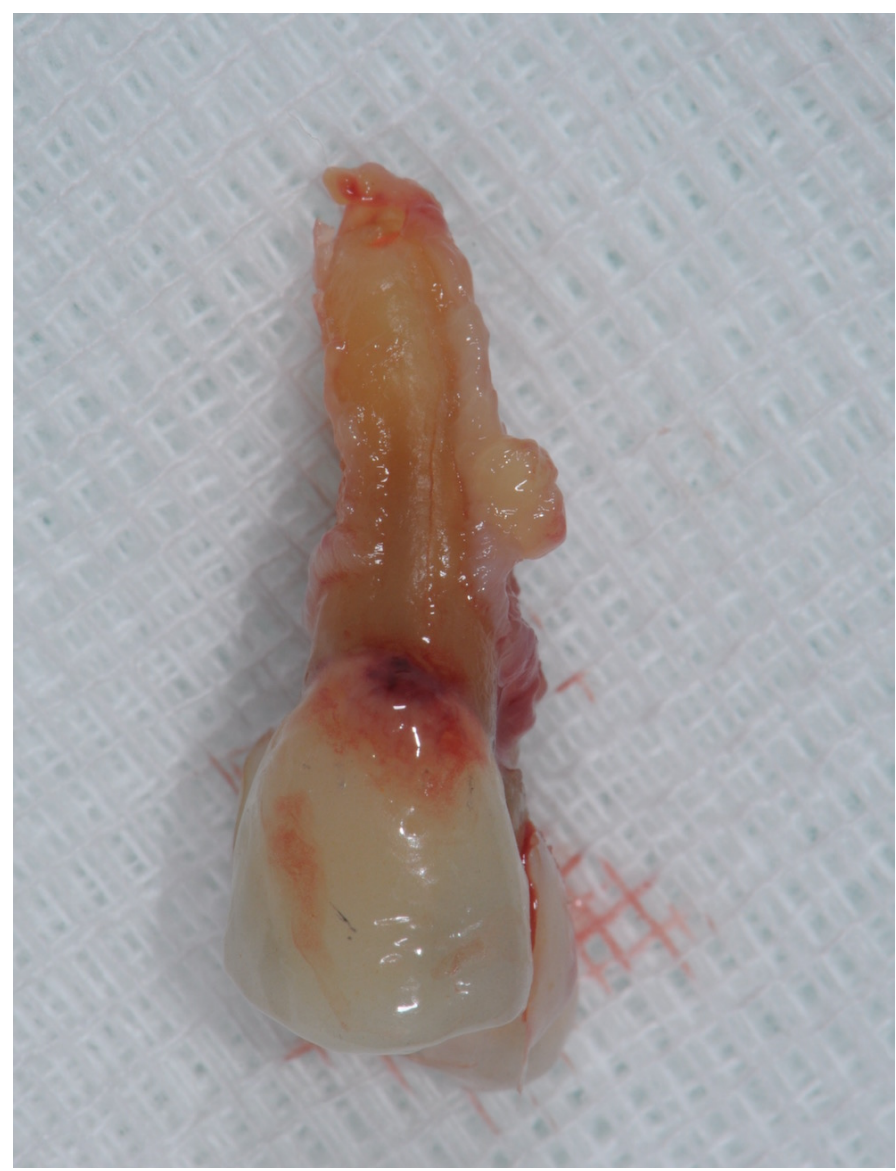

Figure 2

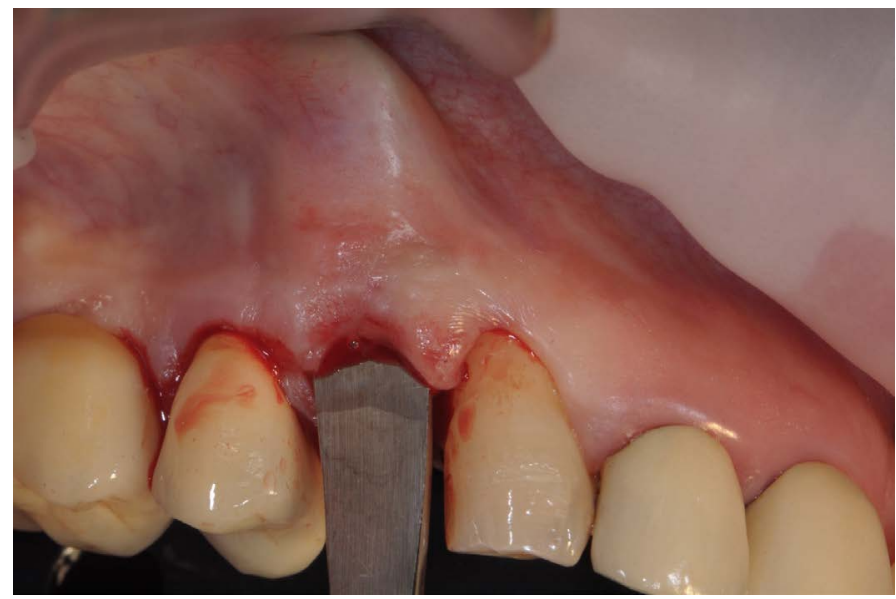

Figure 3 
Todisco M (2018) Immediate alveolar buccal bone plate reconstruction. A simplified technique with 28 consecutive cases and 2- to 4-year follow-up. Case reports with hard tissue and aesthetic evaluation

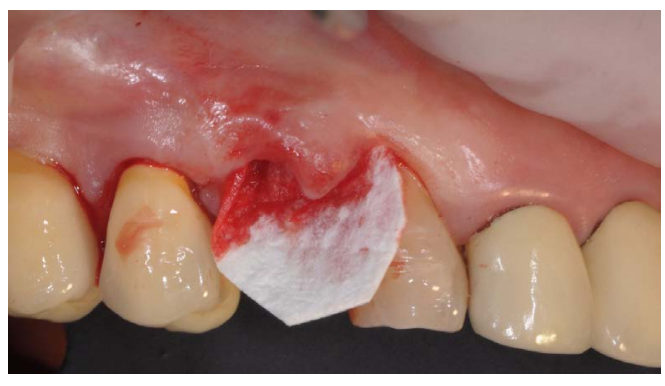

Figure 4

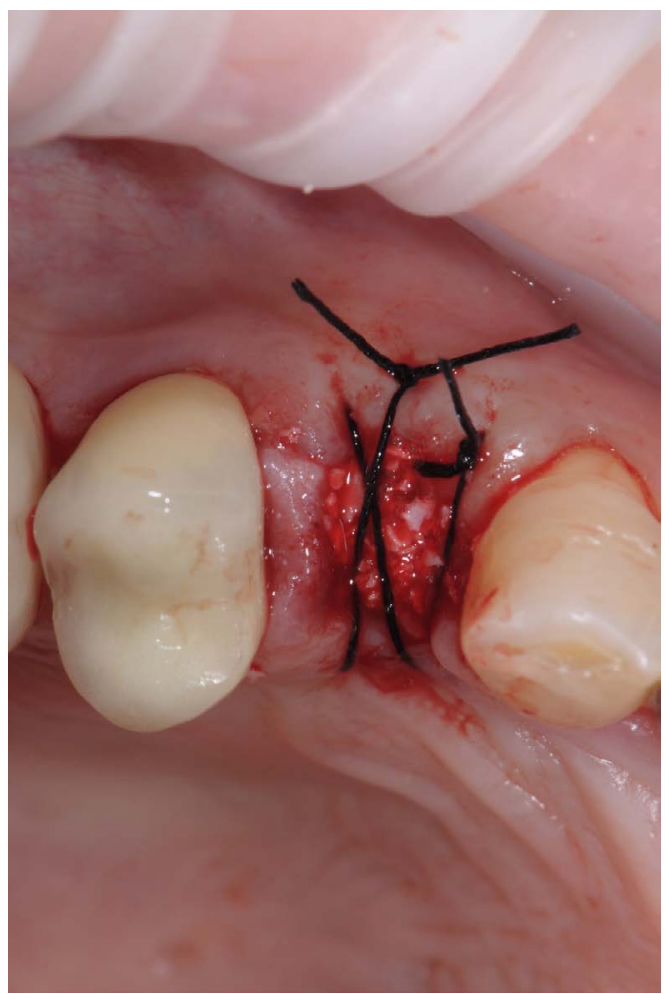

Figure 5

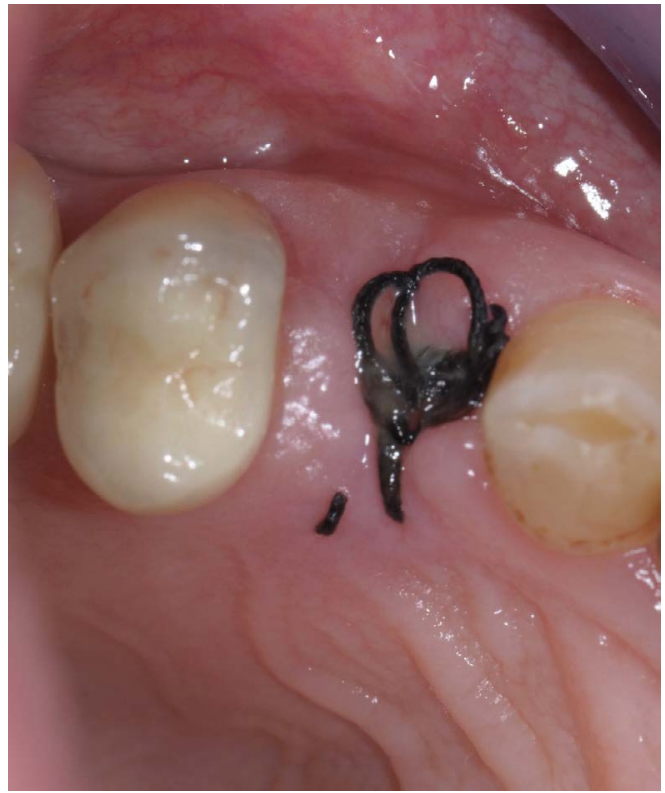

Figure 6 
Todisco M (2018) Immediate alveolar buccal bone plate reconstruction. A simplified technique with 28 consecutive cases and 2- to 4-year follow-up. Case reports with hard tissue and aesthetic evaluation

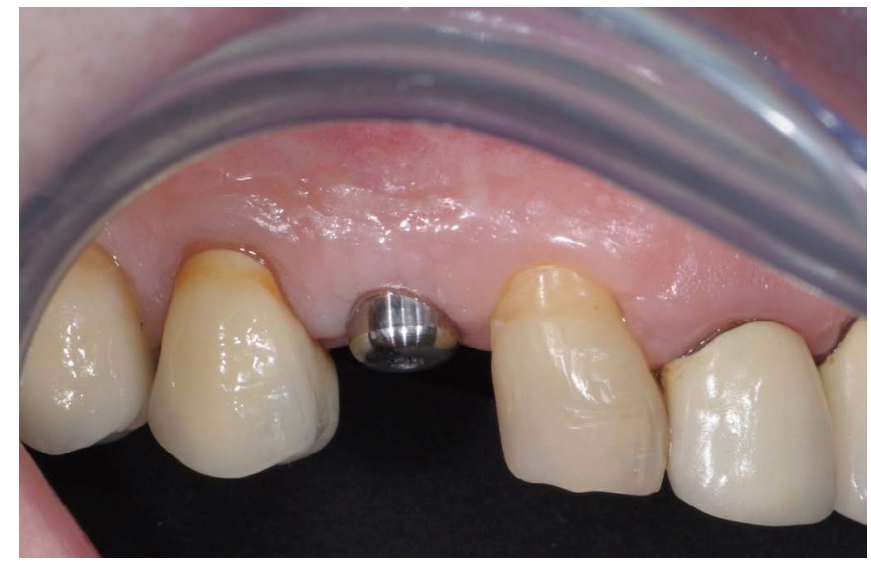

Figure 7

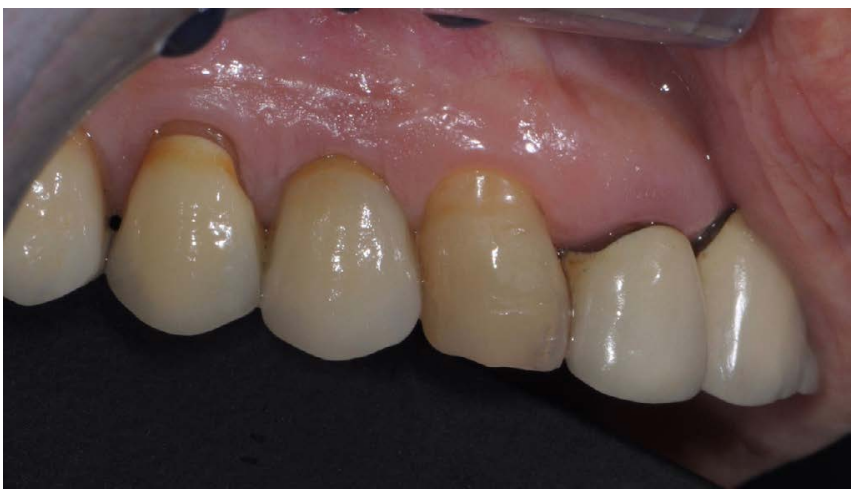

Figure 8

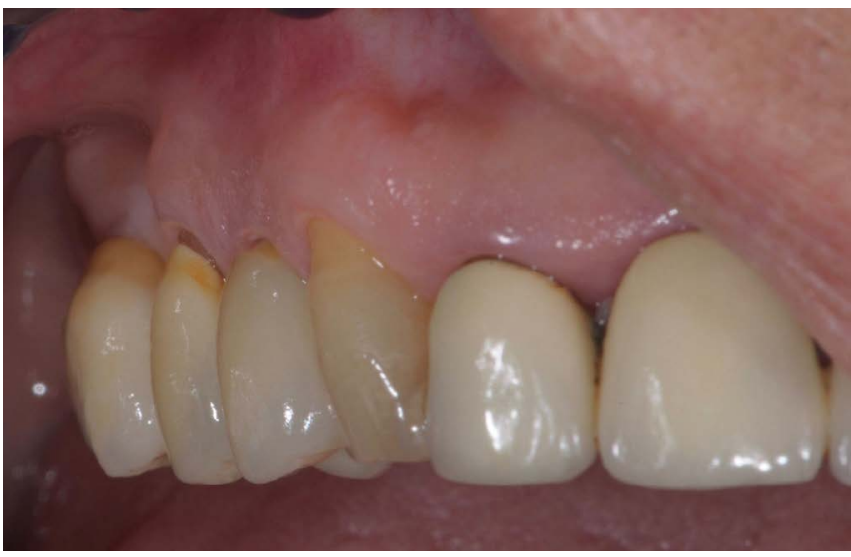

Figure 9

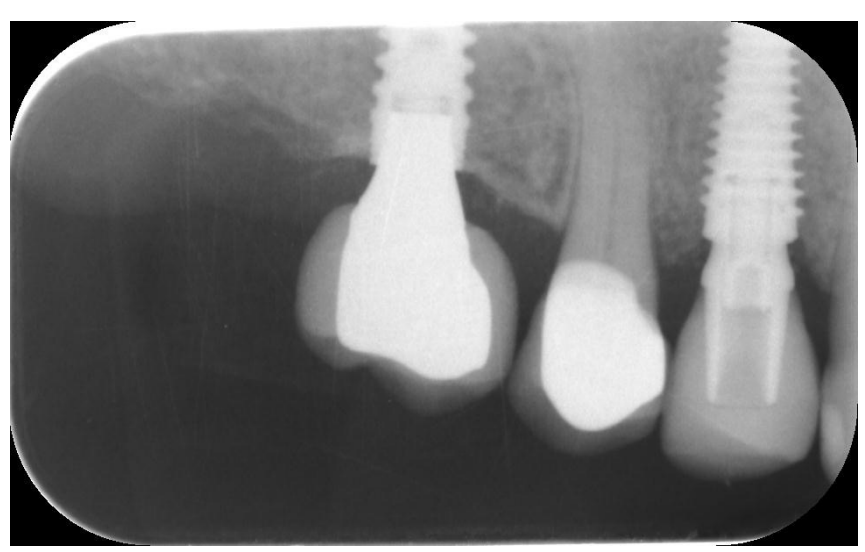

Figure 10 


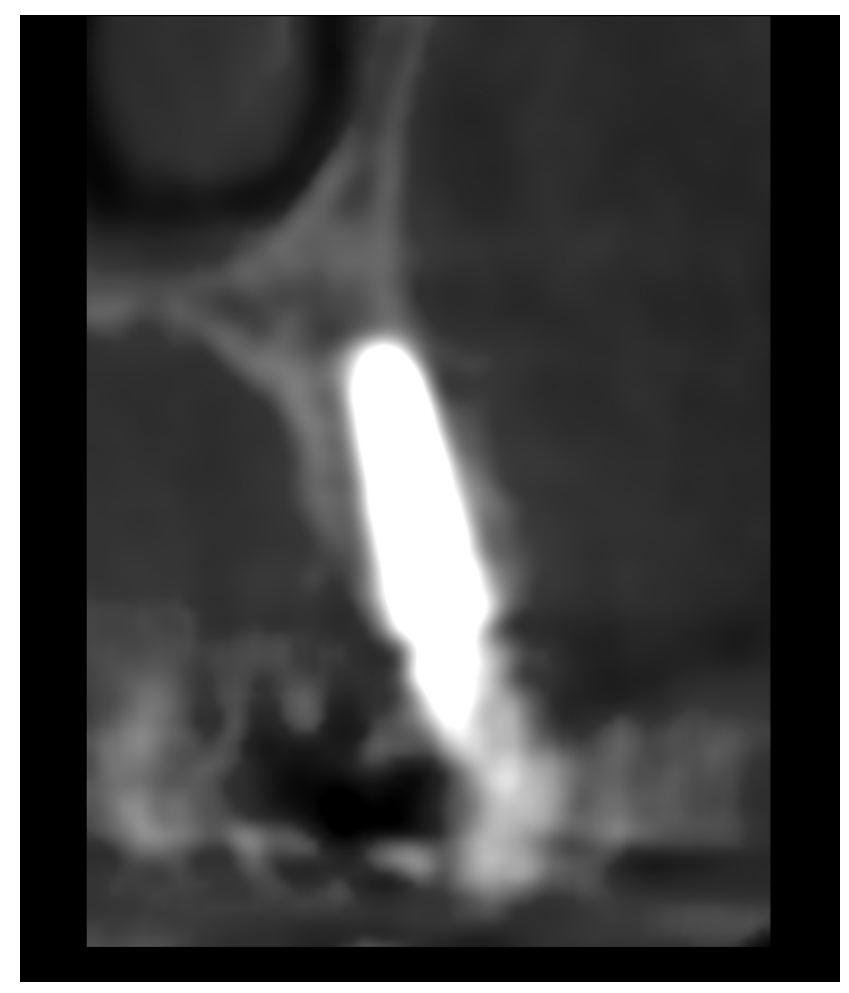

Figure 11

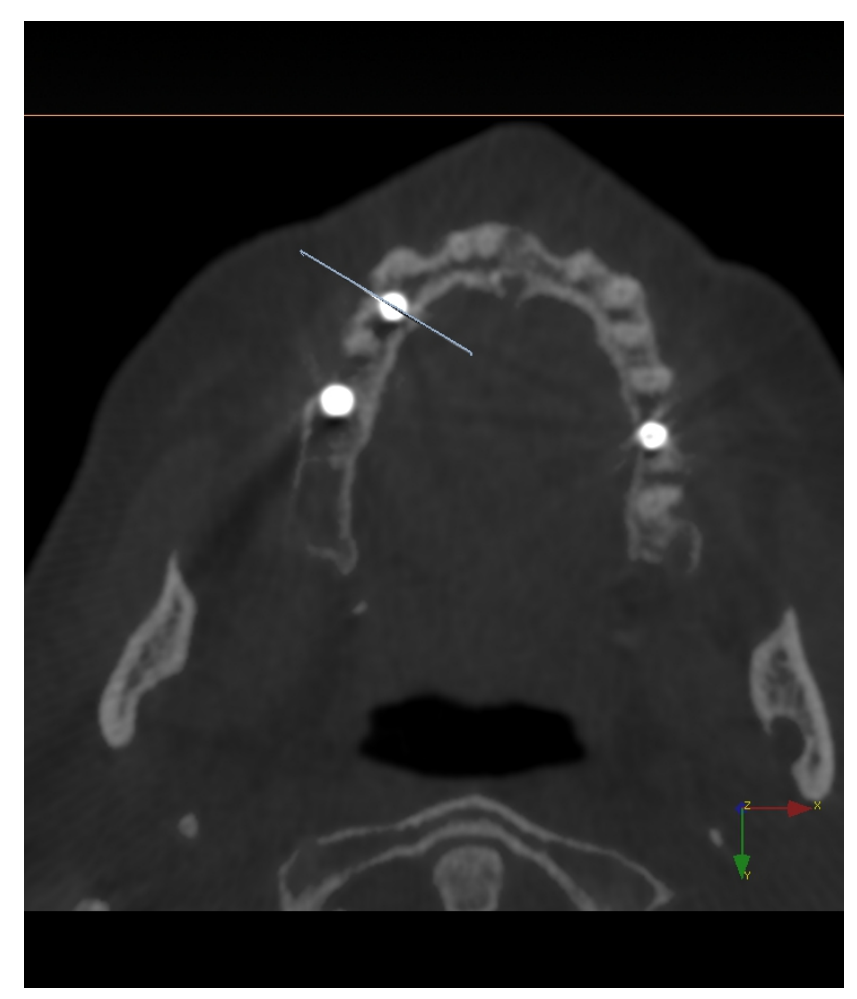

Figure 12

Figures 1-12. Clinical case

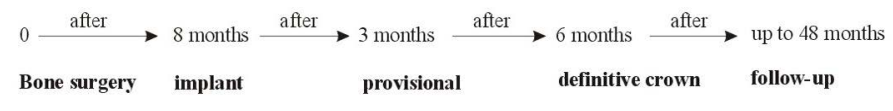

Figure 13. Protocol time table

\section{Hard tissue evaluation}

The $\mathrm{CBCT}$ images were acquired with a $3 \mathrm{D}$ cone-beam dental machine (Gendex i-CAT GXCB-500; KaVo Dental GmbH, Biberach, Germany). The scans were performed with the following technical parameters: $120 \mathrm{kV}, 18.54 \mathrm{~mA}$, a scan time of 8.9 seconds, and a voxel size of $0.3 \mathrm{~mm}$.

A new CBCT scan (second CBCT) was performed to examine stability over time and measure the thickness of the buccal bone plate. At the second CBCT examination in 2016, the implants had 2 to 4 years of follow-up (average 3 years).

For the scan procedure, the occlusal planes were oriented parallel to the horizontal plane.

Using the distance measurement tool, the thickness of the labial bone was measured perpendicular to the implant surface at $2 \mathrm{~mm}$ and $4 \mathrm{~mm}$ from the implant shoulder on the image display of the dental CBCT scan (Table 3).

\section{Soft tissue evaluation}

The Pink Esthetic Score (PES) by Fürhauser et al. [10] was used to evaluate the aesthetic outcome of the peri-implant soft tissues after a mean period of three years (including six months with a provisional crown during the "tissue conditioning" phase before concluding with a definitive porcelain crown). The observer clinicians were calibrated before the study as suggested by Fürhauser et al. [10] Briefly, each single-tooth implant was photographed with a digital camera (D90, Nikkor Medical Objective circular flash; Nikon Corporation, Tokyo, Japan). The photographs were magnified to twice the original size and printed out on DIN A4 sheets together with the list of variables. The interval between the two assessments was reduced to 3 weeks (from the 4 weeks suggested by Fürhauser et al. [10]).

To reduce any bias from the first viewing, the order of the photographs was reversed for the second viewing.

The PES index includes 7 variables: mesial papilla, distal papilla, midfacial level, midfacial contour, alveolar process deficiency, soft tissue colour and soft tissue texture.

Each variable is assessed with a 2-1-0 score, with 2 being the best, and 0 being the poorest score. As a result, the best score that can be attained is a 14 .

The authors arbitrarily set the PES score cut-offs and considered

12-14/14 a perfect outcome,

9-11/14 a good outcome,

and under 1-8/14 a bad outcome.

The mesial and distal papilla were evaluated for completeness, incompleteness or absence (with scores of 2, 1, and 0, respectively).

All other PES parameters were assessed comparing the replaced tooth with the neighbouring teeth and the clinical situation before treatment.

\section{Patient aesthetics evaluation (PEE)}

Patient satisfaction with aesthetics was evaluated with a questionnaire 15 months after loading the implant. A member of the staff who was not involved in the treatment asked patients to select among 3 scores (1-bad, 2 -good, 3 - excellent) to indicate their personal aesthetic evaluation. 
Todisco M (2018) Immediate alveolar buccal bone plate reconstruction. A simplified technique with 28 consecutive cases and 2- to 4-year follow-up. Case reports with hard tissue and aesthetic evaluation

Table 3. Data on the bone thickness at the coronal point and midpoint

\begin{tabular}{|c|c|c|c|}
\hline & $\begin{array}{l}\text { Time since implant } \\
\text { placement (mos) }\end{array}$ & $\mathrm{CP}(\mathrm{mm})$ & MP (mm) \\
\hline 1 & 48 & 2.13 & 2.35 \\
\hline 2 & 48 & 2.40 & 3.01 \\
\hline 3 & 47 & 1.95 & 2.25 \\
\hline 4 & 46 & 2.60 & 3.20 \\
\hline 5 & 45 & 2.10 & 2.85 \\
\hline 6 & 45 & 1.87 & 2.34 \\
\hline 7 & 44 & 2.40 & 2.56 \\
\hline 8 & 42 & 1.55 & 1.78 \\
\hline 9 & 42 & 2.50 & 2.78 \\
\hline 10 & 41 & 2.00 & 2.15 \\
\hline 11 & 41 & 2.05 & 2.32 \\
\hline 12 & 41 & 1.99 & 2.40 \\
\hline 13 & 40 & 2.18 & 2.30 \\
\hline 14 & 40 & 2.47 & 3.05 \\
\hline 15 & 40 & 2.23 & 2.95 \\
\hline 16 & 39 & 2.10 & 2.48 \\
\hline 17 & 39 & 1.54 & 1.80 \\
\hline 18 & 38 & 1.95 & 2.25 \\
\hline 19 & 38 & 2.54 & 2.68 \\
\hline 20 & 37 & 1.38 & 1.90 \\
\hline 21 & 36 & 2.60 & 2.96 \\
\hline 22 & 36 & 1.48 & 2.30 \\
\hline 23 & 36 & 2.10 & 2.59 \\
\hline 24 & 33 & 1.50 & 2.00 \\
\hline 25 & 30 & 2.32 & 2.54 \\
\hline 26 & 27 & 1.95 & 2.35 \\
\hline 27 & 27 & 1.22 & 1.90 \\
\hline \multirow[t]{2}{*}{28} & 25 & 2.00 & 2.48 \\
\hline & Mean & 2.03 & 2.44 \\
\hline
\end{tabular}

$\mathrm{CP}=$ coronal point; $\mathrm{MP}=$ midpoint

\section{Results}

All the patients healed uneventfully after each surgical step. At 2 to 4 years after the placement of implants, all the implants (28/28) were stable, and none had lost osseointegration. This finding corresponded to an overall cumulative implant survival rate of $100 \%$.

\section{Hard tissue}

Eight months after surgery for reconstruction of the buccal bone plate, СBCT confirmed the complete re-building of the defects in all cases.

Flap surgery was performed for the implant placement, and in all the patients, the regenerated hard tissue appeared clinically well mineralized and impossible to penetrate with a periodontal probe.

All the implants were positioned inside the "bone housing", and no signs of resorption were evident.

After a mean of three years of follow-up after the implant surgery, a new dental CBCT examination showed a very stable buccal bone and re-corticalization of the facial socket wall. The total thickness of the buccal bone wall was measured at two horizontal lines perpendicular to the long axis of the implant. The most coronal point (CP) was taken 2 $\mathrm{mm}$ from the implant shoulder, and the second point (midpoint, MP) was $4 \mathrm{~mm}$ from the implant shoulder. The measurements are listed in table 3.

\section{Soft tissue PES after a mean of $\mathbf{3 6}$ months of follow-up}

The aesthetic outcomes comparing the soft tissues of the replaced teeth with the initial clinical status and those of neighbouring teeth are listed in tables 4 and 5. All 7 PES parameters were analyzed twice by two independent operators.

There was a total of 784 data points from the 2 observers, 7 parameters, 28 patients and 2 evaluations.

The overall mean PES (operators I and II for each of 2 assessments) was 13.374 (SD 0.068), indicating a perfect result for all the parameters. There were very slight inter- and intra-observer differences. The mean inter-operator PES was 13.321 (SD 0.05) at the first assessment and 13.428 (SD 0) at the second assessment.

The dotted line (Figure 14), calculated using the scores of the two operators at the first and second observations, indicates that three out of $28(10.7 \%)$ cases had a good outcome $(>9$ and $<12)$, and twenty-five out of $28(89.3 \%)$ had a perfect result $(>12)$.

\section{Patient aesthetics evaluation (PEE) after 2 years}

Two years after loading the implant, each patient was asked to provide a score (from 1 to 3 ) to evaluate the aesthetics of the outcome. Eleven patients out of 28 indicated a PEE of 2 , and 17 patients indicated a PEE of 3 .

\section{Discussion}

The aesthetic success of a restoration is determined by the harmony (scalloping) and stability of the hard and soft tissues [11,12].

The main focus of this study was to determine the long-term stability of alveolar buccal bone regenerated using a bone regeneration

Table 4. PES: First observation

\begin{tabular}{|c|c|c|c|c|c|c|c|c|}
\hline Parameters & I Operator & $\mathbf{0}$ & $\mathbf{1}$ & $\mathbf{2}$ & II Operator & $\mathbf{0}$ & $\mathbf{1}$ & $\mathbf{2}$ \\
\hline Mesial papilla & & 0 & 3 & 25 & & 0 & 4 & 24 \\
\hline Distal papilla & & 0 & 4 & 24 & & 0 & 4 & 24 \\
\hline Midfacial level & & 0 & 1 & 27 & & 0 & 3 & 25 \\
\hline Midfacial contour & & 0 & 3 & 25 & & 0 & 4 & 24 \\
\hline Alveolar deficiency & & 0 & 0 & 28 & & 0 & 0 & 28 \\
\hline Soft tissue color & & 0 & 5 & 23 & & 0 & 4 & 24 \\
\hline Soft tissue texture & & 0 & 2 & 26 & & 0 & 1 & 27 \\
\hline
\end{tabular}

Table 5. PES: second observation

\begin{tabular}{|c|c|c|c|c|c|c|c|c|}
\hline Parameters & I operator & $\mathbf{0}$ & $\mathbf{1}$ & $\mathbf{2}$ & II operator & $\mathbf{0}$ & $\mathbf{1}$ & $\mathbf{2}$ \\
\hline Mesial papilla & & 0 & 3 & 25 & & 0 & 3 & 25 \\
\hline Distal papilla & & 0 & 3 & 25 & & 0 & 3 & 25 \\
\hline Midfacial level & & 0 & 2 & 26 & & 0 & 2 & 26 \\
\hline Midfacial contour & & 0 & 2 & 26 & & 0 & 4 & 24 \\
\hline Alveolar deficiency & & 0 & 0 & 28 & & 0 & 0 & 28 \\
\hline Soft tissue color & & 0 & 5 & 23 & & 0 & 3 & 25 \\
\hline Soft tissue texture & & 0 & 1 & 27 & & 0 & 1 & 27 \\
\hline
\end{tabular}

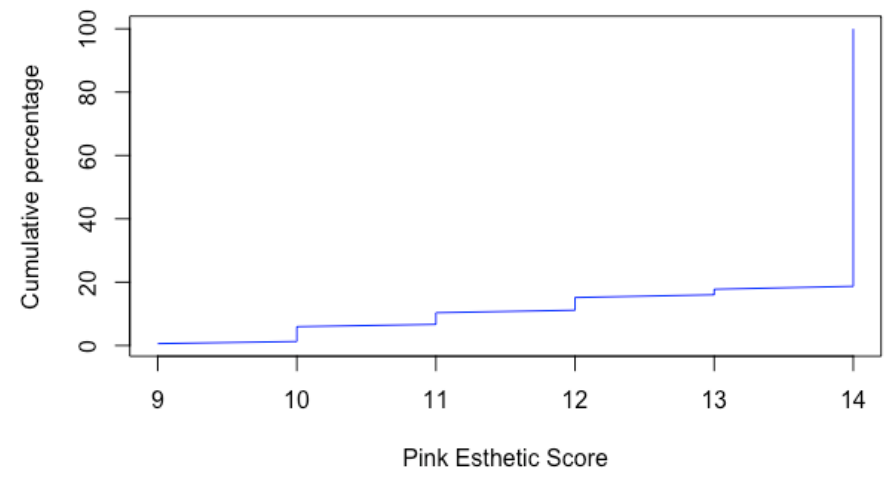

Figure 14. Dotted line 
Todisco M (2018) Immediate alveolar buccal bone plate reconstruction. A simplified technique with 28 consecutive cases and 2- to 4-year follow-up. Case reports with hard tissue and aesthetic evaluation

technique to obtain a facial wall of sufficient height and thickness to serve as support for soft tissues. The aesthetic outcome of the treatment was also evaluated.

In this study, a series of 28 patients without facial socket bone were treated with cross-linked collagen resorbable membranes and heterologous bone. In this technique, the goal is guided bone regeneration of the buccal bone and not socket preservation. The purpose of the membrane is to contain the graft, which in turn prevents the invasion of soft tissue into the socket, and thus, bone cells from the socket walls are then able to repopulate the defect, forming new bone.

Elian et al. [13] proposed a similar augmentation procedure ("Icecone technique"), which was performed using a collagen membrane in the buccal side of the socket. This socket repair technique was carried out utilizing a flapless extraction with care not to disturb the interproximal papillae and labial soft tissue. As graft material, these authors used a small-particle, mineralized cancellous freeze-dried bone allograft. The membrane was then sutured with two or three sutures to the palatal tissue. No clinical evaluation with a reflection flap or 3D X-ray examination was reported. In contrast, with the technique presented in the present study, the collagen membrane was left exposed in the coronal aspect.

In our study, eight months after bone regeneration, submerged implants were placed and then loaded after 3 months for a six-month provisional phase to "drive" the soft tissue morphology, and the treatment was concluded with a lithium-disilicate glass-ceramic as the definitive restoration. After an average of 3 years of follow-up, the implant survival rate was $100 \%$, and hard tissue evaluations and pink aesthetic observations were performed.

Eight months after bone surgery, all the patients had facial socket walls that were completely reconstructed, clinically very stable and well mineralized.

The thickness of the facial bone wall was examined with a $3 \mathrm{D}$ radiograph. Currently, the CBCT technology offers excellent image quality with a clear reduction in radiation exposure to the patient compared with dental CT scans. The CBCT measurement of the bone thickness 2 and $4 \mathrm{~mm}$ from the implant shoulder confirmed hard tissue stability after a mean of 3 years of follow-up. The mean thickness was $2.03 \mathrm{~mm}$ (SD 0.382) for the CP and $2.44 \mathrm{~mm}$ (SD 0.387) for the MP.

In a follow-up study of both immediate and delayed implants and GBR with a CBCT examination in cases involving the correction of deficiencies of the labial bone, Miyamoto and Obama [7] demonstrated that gingival recession is significantly less using a delayed two-stage placement method compared to immediate placement and that vertical bone resorption and gingival recession can be mitigated if $\geq 2 \mathrm{~mm}$ of labial bone thickness is maintained. In that study, the authors used non-resorbable or collagen membranes to reconstruct the buccal wall of the socket, with better results obtained with the non-resorbable membranes and a mixture of an organic bovine bone matrix and freeze-dried bone allograft.

In the present study, very good PESs were noted, indicating a high stability of the soft tissues. According to Miyamoto and Obama,7 these aesthetic outcomes are associated with a mean buccal bone thickness $\geq 2 \mathrm{~mm}$.

In evaluating the delayed two-stage method, Grunder et al. [14] reported that labial alveolar bone thickness should be at least $2 \mathrm{~mm}$ to prevent gingival recession.
In a study that aimed to evaluate with a CBCT examination the dimensions of bone and soft tissue at the buccal aspect of immediately placed implants in humans over a 7-year period, no buccal bone was detected in one-third of the implants, and in this group of patients, the mucosal margin was located $1 \mathrm{~mm}$ more apically [8].

In cases of the complete absence of buccal bone after a tooth extraction, an immediate single implant treatment may be a risky procedure in terms of hard and soft tissue stability. According to a review article, immediate implants have an increased risk of advanced midfacial recession [15].

In three of four studies with data on the parameter of interest, advanced midfacial recession was an infrequent finding affecting $<10 \%$ of the implant patients [16-18], but in contrast with Chen and Buser [15] these studies only included patients with an intact buccal bone wall and a thick gingival biotype.

Patients with a facial osseous defect may not be considered candidates for immediate implant treatment because advanced midfacial recession seems inevitable [4].

In the present study, we considered all the patients to have intact facial socket bone after the reconstruction procedure, but when considering aesthetic results only, the "worst" performance (PES < 12 and $>9$ ) was found in patients with a thin gingival biotype, who composed $18 \%$ of the sample. Therefore, not only the labial bone thickness but also the gingival biotype seems to affect the aesthetic outcome, in accordance with previous studies [16-18].

The position of the implant shoulder seems to be another crucial aspect. In a clinical study, the aesthetic outcome of 42 single-unit, immediately placed implants was analyzed. The investigators reported that those implants with a buccal shoulder position had three times more recessions than the implants with a palatal shoulder position [19].

\section{Conclusions}

The buccal bone reconstruction technique presented in this study had good and stable results after a mean of three years of follow-up. One of the objectives of this prospective study was to monitor changes in the hard and soft tissues after reconstruction of the facial bone.

The aesthetic success of a restoration is determined by the harmony of the hard and soft tissues, and as a consequence, a high patient aesthetic satisfaction can likely be obtained with good management of the various aspects of implant rehabilitation. It should be stressed that not only the surgery but also the prosthetic procedure and the wait time to reach the optimal maturation of the hard and soft tissues are the ultimate goals of a successful therapy.

More research is required to further explore this issue and to optimize adjunctive procedures during the implant placement. The small sample size is a considerable limitation, which must be taken into account when interpreting the findings of the present study.

The authors do not have any financial interest, either directly or indirectly, in the products listed in this study.

\section{References}

1. Pjetursson BE, Tan K, Lang NP, Bragger U, Egger M, et al. (2004) A systematic review of the survival and complication rates of fixed partial dentures (FPDs) after an observation period of at least 5 years. Clin Oral Implants Res 15: 625-642. [Crossref]

2. De Rouck T, Collys K, Cosyn J (2008) Single-tooth replacement in the anterior maxilla by means of immediate implantation and provisionalization: A review. Int J Oral Maxillofac Implants 23: 897-904. [Crossref] 
Todisco M (2018) Immediate alveolar buccal bone plate reconstruction. A simplified technique with 28 consecutive cases and 2- to 4-year follow-up. Case reports with hard tissue and aesthetic evaluation

3. Garber DA, Salama MA, Salama H (2001) Immediate total tooth replacement. Compend Contin Educ Dent 22: 210-216, 218. [Crossref]

4. Kan JY, Rungcharassaeng K, Sclar A, Lozada JL (2007) Effects of the facial osseous defect morphology on gingival dynamics after immediate tooth replacement and guided bone regeneration: 1-year results. J Oral Maxillofac Surg 65: 13-19. [Crossref]

5. Lindeboom JA, Tjiook Y, Kroon FH (2007) Immediate placement of implants in periapical infected sites: A prospective randomized study in 50 patients. Oral Surg Oral Med Oral Pathol Oral Radiol Endod $101:$ 705-710. [Crossref]

6. Cordaro L, Torsello F, Roccuzzo M (2009) Clinical outcome of submerged vs. nonsubmerged implants placed in fresh extraction sockets. Clin Oral Implants Res 20: 1307-1313. [Crossref]

7. Miyamoto Y, Obama T (2011) Dental cone beam computed tomography analyses of postoperative labial bone thickness in maxillary anterior implants: Comparing immediate and delayed implant placement. Int J Periodontics Restorative Dent 31 : 215-225. [Crossref]

8. Benic GI, Mokti M, Chen CJ, Weber HP, Hammerle CH, et al. (2012) Dimensions of buccal bone and mucosa at immediately placed implants after 7 years: A clinical and cone beam computed tomography study. Clin Oral Implants Res 23: 560-566. [Crossref]

9. Buser D, Martin W, Belser UC (2004) Optimizing esthetics for implant restorations in the anterior maxilla: Anatomic and surgical considerations. Int J Oral Maxillofac Implants 19: 43-61. [Crossref]

10. Fürhauser R, Florescu D, Benesch T, Haas R, Mailath G, et al. (2005) Evaluation of soft tissue around single-tooth implant crowns: The pink esthetic score. Clin Oral Implants Res 2005; 16: 639-644. [Crossref]
11. Touati B (1995) Improving aesthetics of implant-supported restorations. Pract Periodontics Aesthet Dent 7: 81-92. [Crossref]

12. Grunder U, Spielman HP, Gaberthuel T (1996) Implant-supported single tooth replacement in the aesthetic region: A complex challenge. Pract Periodontics Aesthet Dent 8: 835-842. [Crossref]

13. Elian N, Cho SC, Froum S, Smith RB, Tarnow DP (2007) A simplified socket classification and repair technique. Pract Proced Aesthet Dent 19: 99-104. [Crossref]

14. Grunder U, Gracis S, Capelli M (2005) Influence of the 3-D bone-to-implant relationship on esthetics. Int J Periodontics Restorative Dent 25: 113-119. [Crossref]

15. Chen ST, Buser D (2009) Clinical and esthetic outcomes of implants placed in postextraction sites. Int J Oral Maxillofac Implants 24: 186-217. [Crossref]

16. Canullo L, Iurlaro G, Iannello G (2009) Double-blind randomized controlled trial study on post-extraction immediately restored implants using the switching platform concept: Soft tissue response. Preliminary report. Clin Oral Implants Res 20: 414-420. [Crossref]

17. Cosyn J, Eghbali A, De Bruyn H, Collys K, Cleymaet R, et al. (2011) Immediate singletooth implants in the anterior maxilla: 3-year results of a case series on hard and soft tissue response and aesthetics. J Clin Periodontol 38: 746-753. [Crossref]

18. Raes F, Cosyn J, Crommelinck E, Coessens P, De Bruyn H (2011) Immediate and conventional single implant treatment in the anterior maxilla: 1-year results of a case series on hard and soft tissue response and aesthetics. J Clin Periodontol 38: 385-394. [Crossref]

19. Evans CD, Chen ST (2008) Esthetic outcomes of immediate implant placements. Clin Oral Implants Res 19: 73-80. [Crossref]

Copyright: (C2018 Todisco M. This is an open-access article distributed under the terms of the Creative Commons Attribution License, which permits unrestricted use, distribution, and reproduction in any medium, provided the original author and source are credited. 